\title{
Food on the table, shoes on our feet
}

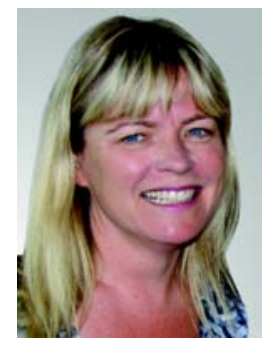

Ruth Armstrong Senior Deputy Editor

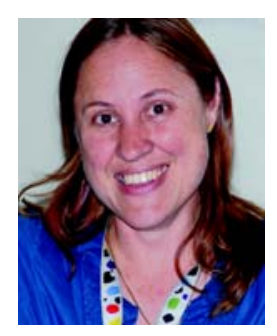

Ann Gregory Acting Editor

mja@mja.com.au

doi: 10.5694/mjal3.c0121

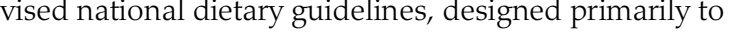
help Australians make better nutritional choices, they voice concern that some of the recommendations will not do the world as a whole any favours. In particular, increasing Australians' consumption of fish may not be the best strategy, given that fish stocks, globally, are collapsing at an alarming rate.

Public health exponents have been telling us for some time that Australia's major food-related disease - obesity - has wide-ranging repercussions that are not evenly spread throughout society. In a study of women who gave birth in Victoria's rural Goulburn Valley, Cunningham and
Teale found that about two in three women were overweight or obese, with increased rates of associated complications, which the authors say may have implications for rural maternity service resourcing (page 39). Obesity-related chronic conditions such as type 2 diabetes are also thought to be a factor in the rates of erectile dysfunction in Indigenous men reported by Adams and colleagues (page 33).

Playing any role in health and health care can be daunting, but there is some advice and inspiration in this issue, to help as you don your running shoes for the year ahead. Kirby (page 15) offers a single shard of advice to British Prime Minister David Cameron, which will resonate with Australian readers — avoid making any new promises on health care delivery during 2013, as the odds are against them being kept. Addressing doctors, Wein explains eloquently what not to do in one's daily work of improving health care and upholding the tenets of our fine profession (page 51).

Some inspiring doctors are remembered in this issue, with tributes to an Australian physician who left an indelible legacy in Tanzania (page 55), a West Papuan doctor who devoted 40 years of service to Papua New Guinean medicine as a physician and teacher (page 56), and a true champion of women's health in Australia and abroad (page 56).

Here at the MJA, we are also mourning the passing and remembering the work of Professor Gavin Mooney, a prominent and colourful health economist who was an advocate of, among other things, involving ordinary citizens in decisions about public health and health care. He would probably have approved of the steady stream of voices calling for a more holistic approach to conversations about the big issues affecting human health. Justice, fairness and compassion in health seemed possible whenever Gavin was in the room. Long may his influence continue!

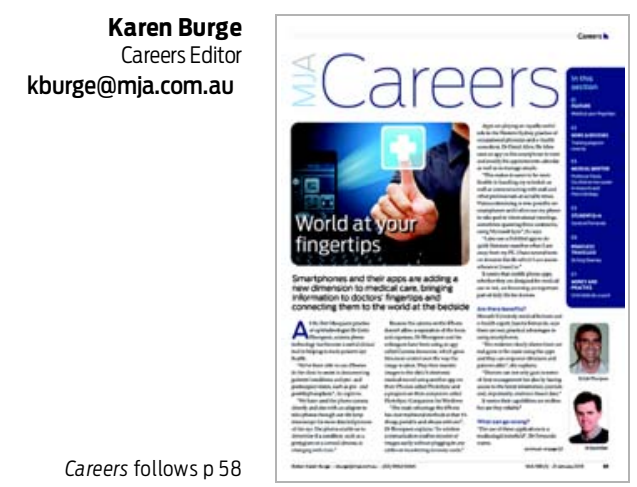

Careers follows $p 58$

\section{Modern medicine}

It wasn't all that long ago mobile phones were so large they could barely fit into your back pocket. Today's smartphones are light, slimline and jam-packed with features that could tempt even the most technologyaverse in the profession. In this issue's Careers section (page C1), we explore the role of smartphones and apps at the bedside, in the office and when on the run. Doctors talk of their experiences, while experts warn of the potential medicolegal risks that come with relying on apps for clinical decision making. Meanwhile, our Medical Mentor (page C5), rheumatologist Professor Flavia Cicuttini, shares her passion for research and her dedication to patient care. In Road Less Travelled (page C6), we meet anaesthetist Dr Greg Downey, who tells us why he hasn't missed a Westmead Hospital Triathlon in 14 years. Finally, Money and Practice (page C7) delves into the nitty-gritty of good versus bad debt, and how you can become debt-free, faster. 
Editor's choice 
Editor's choice 

Editor's choice 